\title{
ASPECTOS EMOCIONAIS E COGNITIVOS EM EFETIVOS DO EXÉRCITO
}

\author{
Gustavo C. Freixa*, Hélio M. Yoshida, Paula Teixeira Fernandes
}

\section{Resumo}

O ambiente militar possui estrutura fundamentada em treinos físicos e preparações psicológicas que visam preparar seus soldados para futuras funções como oficiais. Muitas vezes, o ambiente militar pode influenciar positivamente as atividades diárias na escola e melhorar os aspectos pessoais dos alunos. Tais aspectos influenciam principalmente no desempenho dos cadetes que entraram há pouco tempo no exército, na questão física, na questão da sua qualidade de vida e nas suas funções diárias. Com isso, o objetivo do presente trabalho é avaliar aspectos psicológicos (emocionais e cognitivos) dos alunos ingressantes na Escola Preparatória de Cadetes do Exército (EsPCEx) de Campinas. Serão aplicados questionários validados para avaliar os seguintes aspectos: emocionais = estado de fluxo, estresse, qualidade de vida, resiliência, depressão, ansiedade, autoestima, coping; e cognitivos = atenção e memória.

Palavras-chave: Exército, Ambiente Militar, Psicologia do Esporte

\section{Introdução}

De acordo com a Secretaria Geral do Exército Brasileiro, o valor primordial do meio militar é o Patriotismo, implicando que o militar deve respeitar a soberania e a integridade territorial, com o dever de servir a Pátria, mesmo com o sacrifício de sua própria vida. Assim, alguns aspectos emocionais podem influenciar os militares em suas atividades físicas e funções no ambiente militar, tais como: ansiedade, autoestima, sintomas depressivos, estresse, resiliência, estado de fluxo e coping. Além destes, ressaltamos as funções cognitivas: atenção, raciocínio, memória, percepção e aprendizagem. A avaliação de todos esses aspectos tem significativa relevância e por isso, o presente estudo tem como objetivo avalia-los por meio de questionários aplicados aos cadetes com o mínimo de experiência militar anterior. Assim, poderemos observar como o ambiente militar influencia na parte emocional e cognitiva dos mesmos.

\section{Métodos}

A coleta de dados será feita em agosto na EsPCEx com aproximadamente 200 cadetes homens e 40 cadetes mulheres de faixa etária entre 1822 anos, utilizando os questionários:

- Ficha de identificação

- Dispositional Flow Scale-2 (DFS-2)

- Inventário de Sintomas de Stress de Lipp (ISSL)

- Questionário de Estresse e Recuperação para Atletas (RESTQ-Sport)

- World Health Organization Quality of Life (WHOQOLBreve)

- Escala de Resiliência

- Inventário de Depressão de Beck (BDI)

- Inventário de Ansiedade de BECK (BAI)

- Escala de Autoestima de Rosenberg

- Athletics Coping Skills-28 (ACSI-28BR)

- Teste Pictórico de Memória (TEPIC-M)

- Teste de Atenção Concentrada (Teste AC)
Durante os de janeiro a julho foi feita revisão narrativa nas bases de dados: Doaj, Redalyc, Lilacs, Pubmed, Sc. Direct, Scopus, Scielo e BIREME utilizando as palavras chave "Psicologia Militar" e "Military Psychology", no período de 1998 até 2018, nas línguas espanhol, português e inglês. Na busca refinada foram achados 989 artigos, dos quais somente 388 satisfizeram os requisitos. Os temas mais estudados foram: estresse pós traumático de soldados que participaram de missões em zonas de conflito, ideação suicida e abuso sexual durante o destacamento. Dentre os estudos, poucos abordam a influência do ambiente militar nos cadetes que entraram há pouco tempo neste ambiente e menos ainda são os estudos brasileiros sobre esta temática.

\section{Resultados esperados}

Os resultados servirão de base para o estabelecimento de um perfil psicológico dos estudantes militares e também para pensar em mais estudos na área, enfatizando a saúde psicológica dos militares, visto que a Psicologia do Esporte ainda é uma área com uma importante lacuna científica no meio militar. Assim, unir estes aspectos é fundamental para o desenvolvimento integral dos alunos, dos soldados, da equipe militar e também da ciência brasileira.

\section{Agradecimentos}

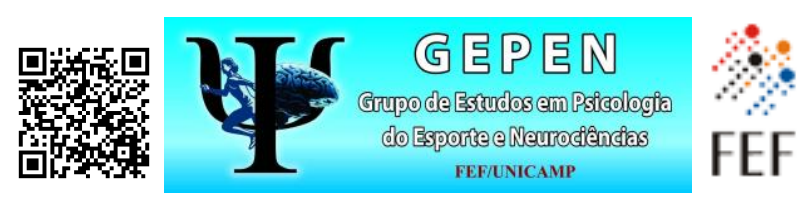

